Article

\title{
Strain Rate Effects in CFRP Used For Blast Mitigation
}

Sarah. L. Orton ${ }^{1, *}$, Vincent P. Chiarito ${ }^{2}$, Christopher Rabalais ${ }^{2}$, Matthew Wombacher ${ }^{1}$ and Stephen P. Rowell ${ }^{2}$

1 University of Missouri Columbia, E2503 Lafferre Hall, Columbia, MO 65211, USA;

E-Mail:mtwf35@mail.missouri.edu

2 U.S. Army Engineer Research and Development Center, 3909 Halls Ferry Road, Vicksburg, MS 39180, USA; E-Mails: Vincent.P.Chiarito@usace.army.mil (V.P.C.);

Christopher.P.Rabalais@usace.army.mil (C.R.); Stephen.p.rowell@usace.army.mil (S.P.R.)

* Author to whom correspondence should be addressed; E-Mail: ortons@missouri.edu; Tel.: +1-573-884-5089; Fax: +1-573-882-4784.

Received: 12 February 2014; in revised form: 17 March 2014 / Accepted: 25 March 2014 / Published: 3 April 2014

\begin{abstract}
The purpose of this research is to gain a better understanding of strain rate effects in carbon fiber reinforced polymer (CFRP) laminates exposed to blast loading. The use of CFRP offers an attractive option for mitigating structures exposed to blasts. However, the effect of high strain rates in CFRP composites commonly used in the civil industry is unknown. This research conducted tensile tests of 21 CFRP coupons using a hydraulically powered dynamic loader. The strain rates ranged from $0.0015 \mathrm{~s}^{-1}$ to $7.86 \mathrm{~s}^{-1}$ and are representative of strain rates that CFRP may see in a blast when used to strengthen reinforced concrete structures. The results of the testing showed no increase in the tensile strength or stiffness of the CFRP at the higher strain rates. In addition, the results showed significant scatter in the tensile strengths possibly due to the rate of loading or manufacture of the coupon.
\end{abstract}

Keywords: carbon fiber reinforced polymers; blast loads; reinforced concrete; strain rate; tensile strength 


\section{Introduction}

Fiber reinforced polymers (FRP) have been used in blast mitigations due to their ability to reach high strengths while being lightweight and easily applied. Specifically, tests by Orton et al. [1], Kim et al. [2], Muszynski and Purcell [3], Razaqpur et al. [4], Wu et al. [5] and Lu et al. [6] have shown the effectiveness of FRP to strengthen reinforced concrete components for blast. Typically the FRP is applied to the back-face of the concrete element as shown in Figure 1. In this configuration the FRP experiences tension due to the bending of the concrete element under the blast. The high strength and lightweight properties allow for the FRP to greatly increase the resistance of a structural member due to these tensile and bending loads, as well as provide a means for reducing fragmentation projectiles while still regulating the amount of mass of the member. This becomes important when considering that the addition of large amounts of mass will increase the overall amount of dead load acting on the columns and foundation of a structure which may approach or exceed their static capacity. However, the question of how the material properties (tensile strength and ductility) of the FRP change at the strain rates applied by blast loading remains unanswered.

Figure 1. Fiber reinforced polymers (FRP) applied to back-face of reinforced concrete element.

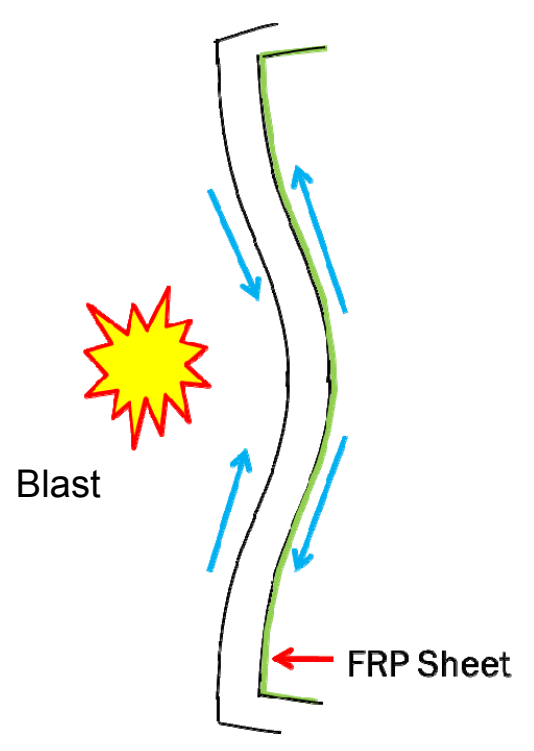

This research specifically considers wet lay-up carbon based FRP (CFRP) in which carbon fibers are saturated with epoxy and applied to a reinforced concrete element on site. In addition, the research considers strain rates representative of what CFRP would experience if applied to a reinforced concrete element under blast loading. Although a blast is a very impulsive load with durations as low as, or less than, $20 \mathrm{~ms}$, the strain rate actually experienced in the CFRP is a function of the movement of the structure after the blast. Consider a CFRP mitigated concrete slab. When the blast occurs the shock wave will move through the concrete very quickly, but due to the interface between the concrete and CFRP the shock wave is reflected when it reaches the CFRP. Therefore the CFRP is not actually loaded with the blast wave. The loading of the CFRP occurs once the entire slab starts to move in response to the blast. For structures under short impulse loads this movement occurs at a rate equal to the natural period of the system. Therefore the strain rate experienced in the CFRP is dependent on the structural system to which the CFRP is attached. The target strain rate for the CFRP under blast 
loading for this research is based on the actual blast tests presented in Orton et al. [1]. For these tests CFRP mitigated concrete slabs measuring $1.2 \mathrm{~m}$ by $2.4 \mathrm{~m}$ with a $13 \mathrm{~cm}$ thickness were tested under blast loads with a scaled range of 0.4 and $0.6 \mathrm{~m} / \mathrm{kg}^{1 / 3}$. Following an analysis procedure presented in Biggs [7] the natural period of the slab is $0.00736 \mathrm{~s}$. If the slab is assumed to deform in a parabolic membrane this means that the strain rate experienced in the CFRP is $1.2 \mathrm{~s}^{-1}$. Based on high speed video images taken during the actual blast tests the strain rate in the CFRP is approximated to be $3 \mathrm{~s}^{-1}$ for the $0.4 \mathrm{~m} / \mathrm{kg}^{3}$ scaled range and $0.75 \mathrm{~s}^{-1}$ for the $0.6 \mathrm{~m} / \mathrm{kg}^{3}$ scaled range. These rates also agree with computational analysis from Mosalam and Mosallam [8] for farther field blasts which indicate strain rates less than $1 \mathrm{~s}^{-1}$. Because different structures will have different natural periods and the CFRP will experience different strain rates, the target strain rate range for the coupon tests was set between 1 and $8 \mathrm{~s}^{-1}$ to be representative a wide range of possible reinforced concrete elements.

It is well known that the rate of loading or strain rate can affect a material's properties. Standard building materials used in structures such as concrete and steel have shown that they perform very differently dynamically than under normal static loading conditions [9]. The UFC 3-340-02 [9] gives dynamic increase factors (DIF) for both steel and concrete to account for the higher strengths reached due to higher strain rates when under a blast scenario. For concrete the DIF starts to increase rapidly above 1.2 once the strain rate exceeds $0.1 \mathrm{~s}^{-1}$. For steel, the grade of steel is important as higher grades of steel show less strain rate effect and there is a higher DIF for the yield strength than for the ultimate strength. For example, grade 60 reinforcement has a DIF of 1.3 for yield and 1.1 for ultimate strength at a strain rate of $1 \mathrm{~s}^{-1}$.

Strain rate may also affect the behavior of CFRP composite materials. However, CFRP made with differing manufacture techniques will have different material properties and therefore different sensitivity to strain rates. Therefore this research considers a type of CFRP that is typically used in the civil industry and may not be comparable to other studies that used a higher quality CFRP common in the aerospace and automotive industries. Furthermore, the CFRP used in this study is made to be applied to reinforced concrete structures using a wet lay-up technique (flexible carbon fiber fabric that is saturated with epoxy at the jobsite). This type of process induces waviness into the material (the surface of the concrete is not perfectly flat) and makes it difficult to control the ratio of carbon fiber to epoxy. Finally, this research will focus on strain rates that might be experienced by CFRP applied to a reinforced concrete member undergoing a blast loading. Although the blast wave loads the structure vary rapidly, the actual rate of strain in the tensile CFRP is much slower.

There have also been numerous studies on fiber reinforced composites, including both CFRP and GFRP (glass fiber reinforced polymer) that points to their viscous nature. Creep in composites has been recognized by many researchers and is primarily due to the matrix supporting stresses in shear deforming under long term loads [10,11]. The matrix is also susceptible to changes in behavior under high loading rates. To further establish material characteristics under high strain rates, in 1997 Sierakowski [12] presented a review of strain rate effects in several different types of composites tested using several different test methods. He found that the fiber orientation, composite type, mode of loading, and strain rate all affect the behavior of the material. For hydraulic/pneumatic tests (such as the one used in this research) he noted that strain rates were limited to 10 to $100 \mathrm{~s}^{-1}$ due to the inertial effects of the load cell and grips and wave propagation effects. Pressure bar tests, such as the Split Hopkinson Pressure Bar, can be used to produce strain rates up to $10,000 \mathrm{~s}^{-1}$ but can only be used on 
relatively small samples. In 2004, Jacob et al. [13] also conducted a review of strain rate effects in polymer material composites. They found that contradictory conclusions and observations have been reported due in part to differences in testing procedures and specimen sizes. In addition Wisnom [14] noticed an important size effect in fiber composite materials. He showed that defects and stress gradients will often cause larger size specimens to fail at lower levels of load. This research into strain rate effects of CFRP is focused on the particular case where the CFRP is applied to a reinforced concrete element experiencing a blast loading. Therefore, the CFRP coupon size has been kept large and made with the same wet lay-up technique used in the application of the CFRP to the concrete in order to best represent the strength of the CFRP in service. Furthermore, the target strain rate range is between 1 and $8 \mathrm{~s}^{-1}$, which is the predicted range of strain rates seen in the CFRP. A hydraulic tension loader was chosen because it could best apply the loads in the strain rate range under question.

In general, previous research has shown that there is some strain rate effect with FRP materials. Welsh and Harding [15] conducted high strain rate tests on a variety of composites utilizing a tension bar configuration. Materials examined in these tension tests included carbon, glass, and Kevlar reinforced polyester resins. It was revealed from these tests that there is a clear effect of strain rate on the ultimate strength of the materials investigated. For the CFRP specimen the tensile strength increased by $50 \%$ over the static strength at a strain rate of $10 \mathrm{~s}^{-1}$. The other significant observation made from this series of tests was of the fracture appearance of the specimens differed at the various dynamic loading rates. Al-Salehi et al. [16] also tested glass, Kevlar, and carbon fibers and found that for strain rates around $20 \mathrm{~s}^{-1}$ the tensile strength was not significantly greater than the static strength but for strain rates of around $100 \mathrm{~s}^{-1}$ increases of $70 \%$ were noted. Gilat et al. [17] further evaluated strain rate effects in carbon/epoxy composites under tensile loading by testing laminates with various fiber orientations. He found that the strain rate effects were more pronounced in composites with $45^{\circ}$ fiber orientations due to greater influence of the resin (matrix) behavior.

There have also been studies using glass FRP (GFRP). Shokrieh and Omidi [18] studied a unidirectional glass/epoxy composite system through the use of a servo-hydraulic test apparatus, specimens over strain rates that ranged from 0.001 to $100 \mathrm{~s}^{-1}$. Their research showed that the tensile strength of the GFRP increased at around $8 \mathrm{~s}^{-1}$. Furthermore, in the lower strain rate range, the fracture surface showed minimal damage and only affected small portions across the specimen width. When the strain rate was increased to higher magnitudes, the damage tended to cross the entire specimen width showing extensive debonding between the fibers and the matrix. Asprone et al. [19] also studied GFRP composites and found tensile strengths increasing by approximately $5 \%$ to $15 \%$ starting at around $10 \mathrm{~s}^{-1}$ strain rates.

Therefore, the previous research shows that there are some strain rate effects in GFRPs at around $8 \mathrm{~s}^{-1}$. Whereas for CFRPs the point at which strain rate affects tensile strength may occur around 10 or $20 \mathrm{~s}^{-1}$. In addition, it is important to note that these tests were not performed on the same type of CFRP as used in this research and were often performed on very small samples of CFRP in a tension bar configuration, therefore there may or may not be a strain rate effect at rates CFRP would see in a blast event.

\section{Experimental Section}

This research tested 21 CFRP laminate coupons in order to study the effects of strain rate in CFRP composites. This study was undertaken to verify dynamic CFRP properties used in blast mitigation 
presented in Orton et al. [1]. CFRP coupons were created through a wet lay-up process and were later tested under uniaxial tension using an $890 \mathrm{kN}$ Dynamic Loader. Strain and load of the CFRP coupons was recorded as a function of time during these tests. Prior to conducting all of the tests, target strain rate regions were developed to ensure a balanced distribution of data points that would allow for adequate conclusions to be drawn from the results. By compiling and analyzing the entire load vs. strain rate data, it can be determined if there are any increases in strength due to dynamic performance within the CFRP specimens.

\subsection{CFRP Coupon Creation}

The CFRP coupons were made in a wet layup process from a unidirectional CFRP fabric typical of that used in the civil construction industry. Manufacture provided properties of the fabric and epoxy are provided in Table 1.

Table 1. Composite Gross Laminate Properties [20].

\begin{tabular}{cc}
\hline Property & Value \\
\hline Composite Tensile Strength & $986 \mathrm{MPa}$ \\
Composite Engineering Strain & 0.01 \\
Composite thickness & $1 \mathrm{~mm}$ \\
Composite Tensile Modulus & $95.8 \mathrm{GPa}$ \\
Dry Fiber tensile strength & $3.79 \mathrm{GPa}$ \\
Dry fiber tensile modulus & $230 \mathrm{GPa}$ \\
Epoxy tensile strength & $72.4 \mathrm{MPa}$ \\
Epoxy tensile modulus & $3.18 \mathrm{GPa}$ \\
\hline
\end{tabular}

During coupon construction, each coupon was immersed in the epoxy and placed between a roller that removed excess epoxy and entrapped air. The coupon then was laid flat on a stiff board to cure (more than $72 \mathrm{~h}$ per manufacturer suggestion), Figure 2, to simulate the application of the CFRP to the reinforced concrete surface. After the CFRP was cured, coupons measuring approximately $7.6 \mathrm{~cm}$ by $40 \mathrm{~cm}$ were cut from the CFRP fabric. Because the application of the CFRP to the surface of the board can distort the thickness of the CFRP, the coupons were cut so that they had the same number of tows in order to ensure the same area of dry fiber in each coupon. The approximate volumetric percentage of fibers was $25 \%$. To minimize grip slippage during the tensile tests, metal plates were machined and epoxied to the ends of each specimen with additional pieces of CFRP as shown in Figures 2 and 3. These plates were later used to mount the CFRP coupons into the $890 \mathrm{kN}$ Dynamic Loader which allowed for eccentric loading and bending to be minimized as much as possible. Coupons (Figure 3) were $7.6 \mathrm{~cm}$ wide to accommodate the initial preload of $44 \mathrm{kN}$ needed in the dynamic tester. The coupon gage length was $20 \mathrm{~cm}$ to allow a gage length more than 2 times the width, and the length of coupon in the grips was $10 \mathrm{~cm}$. When placed in the test fixture the metal tabs of the coupon were clamped and bolted through. 
Figure 2. Carbon fiber reinforced polymer (CFRP) Laminates during Wet-layup Curing.

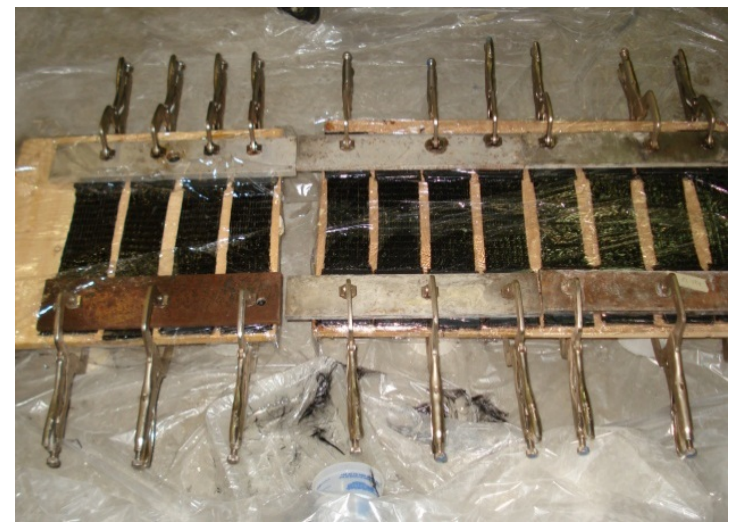

Figure 3. CFRP Coupon.
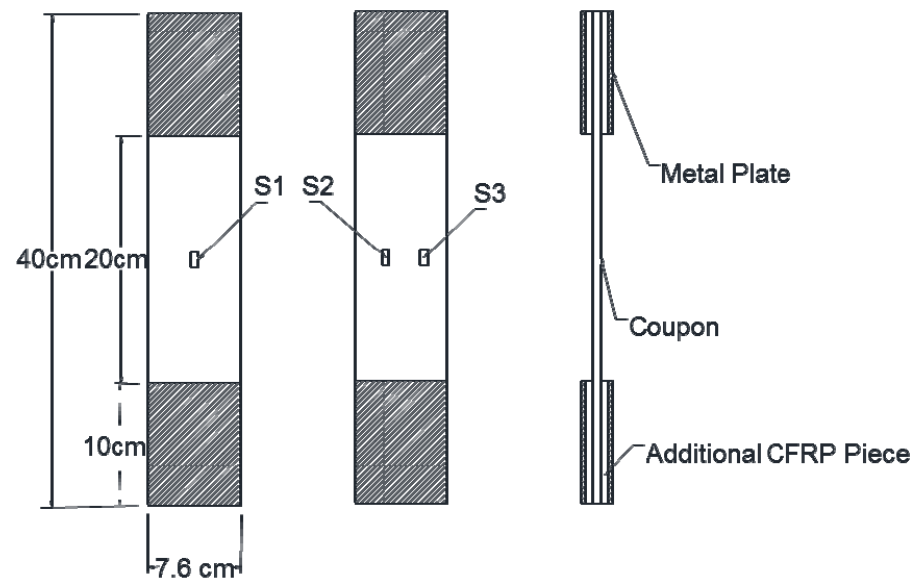

Front

Back

Side

\subsection{Test Setup}

The dynamic loader used in this research (Figure 4) is an apparatus capable of applying concentrated loads over a range of strain rates [21]. Loads are employed when a closed solenoid valve is opened thus producing a sudden release of stowed pressure underneath a piston. The pressure underneath the piston is created by oil that is being pressurized and then held in the accumulators of the system located in the chamber above the piston. When the solenoid valve is released the compressed oil above the piston will rapidly expand forcing the piston downward leading to the load being applied to the specimen. The rate at which the load is applied can be altered by a variable orifice device which changes the opening diameter and flow path of the oil. When loads are applied rapidly with this system, it must be recognized that the inertial forces of the larger masses (load cells and lower grip) must be accounted for when determining the actual load being applied to the specimen. The specimen itself rests within the steel grips of the apparatus which allows for fixed end conditions. 
Figure 4. Schematic $890 \mathrm{kN}$ Dynamic Loader.

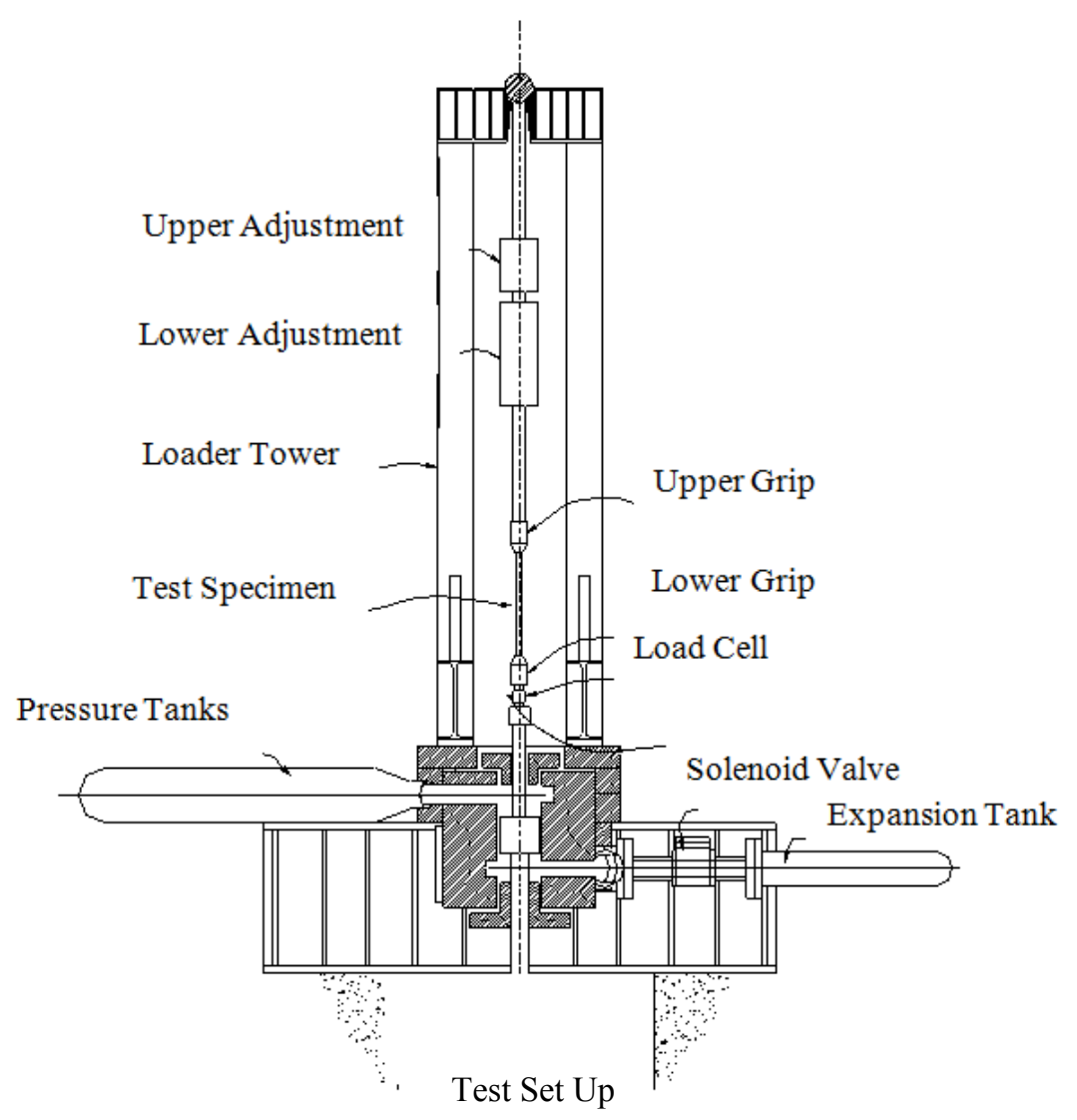

An image of a CFRP coupon in the dynamic loader is shown in Figure 5. The CFRP coupon was bolted between two $6 \mathrm{~mm}$ thick plates using either 6 or 9 bolts tightened to approximately $67 \mathrm{~N} \cdot \mathrm{m}$ of torque. Three load cells were used to capture the applied load as a function of time throughout the tests. A $222 \mathrm{kN}$ load cell and an $890 \mathrm{kN}$ load cell were located above the CFRP specimen while a second $222 \mathrm{kN}$ load cell was placed below the specimen. All three load cells captured the load that the specimen was experiencing as the compressed oil was released and load applied. Since the $222 \mathrm{kN}$ load cell was connected to the lower half of the $890 \mathrm{kN}$ Dynamic Loader and located beneath the CFRP specimen inertial forces had to be considered as previously stated. These inertial forces were determined through the use of two accelerometers placed above and below the specimen.

Three strain gages (S1, S2, and S3) were applied to each CFRP coupon as shown in Figure 3. Any variance in the strain readings due to bending in the coupon would be evident in the strain gage readings. In addition each test was recorded using high speed video. 
Figure 5. CFRP coupon in dynamic loader.

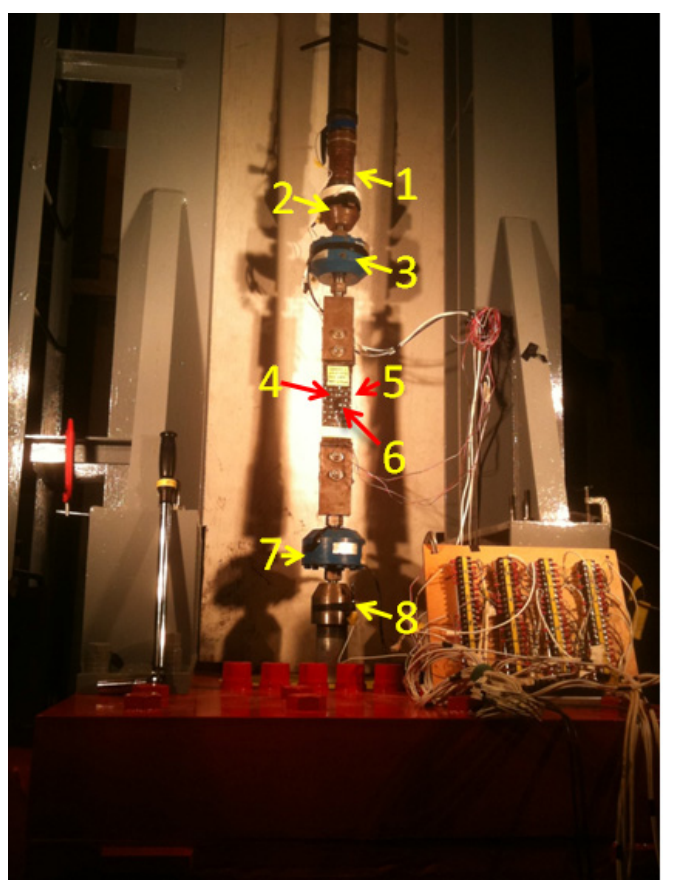

1. Upper $890 \mathrm{kN}$ Load Cell

2. Upper Accelerometer

3. Upper $222 \mathrm{kN}$ Load Cell

4. Strain Gauge, S2; backside of coupon, left quarter point

5. Strain Gauge, S3; backside of coupon, right quarter point

6. Strain Gauge, S1; front, middle point

7. Lower $222 \mathrm{kN}$ Load Cell

8. Lower Accelerometer

\section{Results and Discussion}

Testing of 21 carbon/epoxy coupons occurred in the dynamic loaded mentioned previously. Due to the impulsive nature of the loading the actual rate of loading and strain is not controlled and depends on the response of the test specimen. The strain and loading rates of the test specimens were determined by finding the approximate rate from the time in which the load or strain began to increase until the point of fracture. An example is shown in Figure 6 where the slope of the lines indicates the strain rate. The average strain rate is the average of the approximate rates determined from the three strain gages. Considerably different strains in the three strain gages would indicate misalignment of the coupon and therefore and induced moment. Therefore, coupons in which the strain at failure differed by more than $20 \%$ were removed from the analysis. Loads from the three load cells were generally in agreement therefore only the load measured in the upper $222 \mathrm{kN}$ cell is presented.

Figure 6. Determination of approximate strain rate.

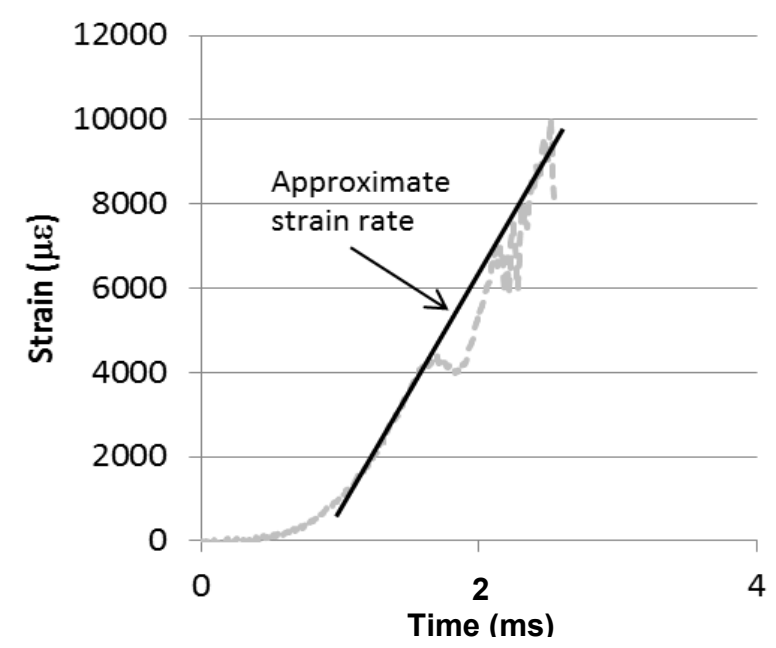


Overall results of the coupon tests can be seen in Figure 7 and Table 2. Test data shows no increase in coupon tensile strength at strain rates less than $8 \mathrm{~s}^{-1}$. However, there is significant variability in the strengths obtained at the different strain rates. The average strength of all the coupons is $840 \mathrm{MPa}$ with a standard deviation of $161 \mathrm{MPa}$. The ultimate tensile strength is less than the manufacture's reported $986 \mathrm{MPa}$ as presented in Table 1. Three coupons that were tested at near static rates (\#15, \#17 and \#18) had an average tensile strength of $1047 \pm 99 \mathrm{MPa}$ which is in line with the manufacture's reported static properties. Therefore, the entire set of coupons tested dynamically showed on average $24 \%$ less tensile strength with almost 1.6 times the standard deviation than the static coupons. Testing of 7 additional coupons with only a $4 \mathrm{~cm}$ width in a static testing machine yielded an average tensile strength of $882 \pm 92 \mathrm{MPa}$. The average strength of the seven additional coupons is closer to the dynamically tested coupons; however the standard deviation of the coupons strengths is $60 \%$ less. The reduction in standard deviation of the statically loaded coupons would seem to indicate that dynamic loading can lead to more variability in the coupon strength. Previous research indicated that the failure surface of dynamically loaded CFRP differed than that of statically loaded CFRP [13]. Higher loading rates may result in an inability to fully distribute load among the fibers leading to premature failure in some dynamically tested coupons. Furthermore, the coupons tensile strength is on average less than the manufacture's reported value. This may be due to the wet lay-up manufacture of the coupons which most closely resembles the field application of the material. The wet lay-up manufacture could lead to additional waviness of the fibers thereby reducing the overall tensile strength.

Figure 7. Peak stress $v s$. average strain rate for all coupons.

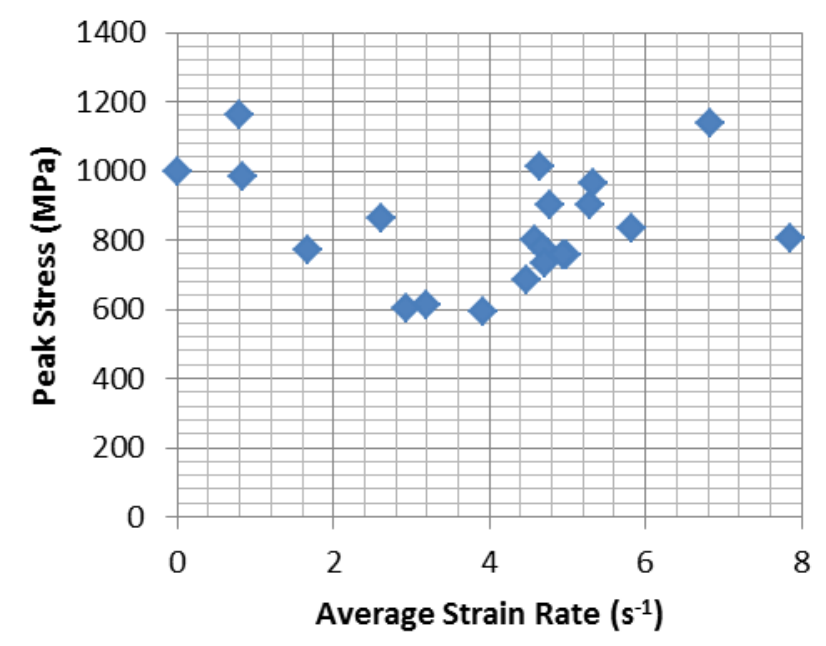


Table 2. Test Results.

\begin{tabular}{|c|c|c|c|c|c|c|c|c|c|c|}
\hline \multirow[b]{2}{*}{ Sample\# } & \multicolumn{2}{|c|}{ S1 } & \multicolumn{2}{|c|}{ S2 } & \multicolumn{2}{|c|}{ S3 } & \multirow[b]{2}{*}{$\begin{array}{c}\text { Average } \\
\text { Strain Rate } \\
\left(\mathbf{s}^{-1}\right)\end{array}$} & \multirow[b]{2}{*}{$\begin{array}{l}\text { Peak } \\
\text { Stress } \\
(\text { MPa) }\end{array}$} & \multirow[b]{2}{*}{$\begin{array}{c}\text { Loading Rate } \\
(\mathrm{MPa} / \mathrm{ms})\end{array}$} & \multirow[b]{2}{*}{$\begin{array}{l}\text { Type of } \\
\text { Fracture }\end{array}$} \\
\hline & $\begin{array}{c}\text { Max } \\
\text { Strain } \\
\left(\mathbf{E}^{-6}\right)\end{array}$ & $\begin{array}{c}\text { Strain } \\
\text { Rate } \\
\left(\mathrm{s}^{-1}\right)\end{array}$ & $\begin{array}{c}\text { Max } \\
\text { Strain } \\
\left(E^{-6}\right)\end{array}$ & $\begin{array}{c}\text { Strain } \\
\text { Rate } \\
\left(\mathbf{s}^{-1}\right)\end{array}$ & $\begin{array}{c}\text { Max } \\
\text { Strain } \\
\left(\mathbf{E}^{-6}\right)\end{array}$ & $\begin{array}{c}\text { Strain } \\
\text { Rate } \\
\left(\mathbf{s}^{-1}\right)\end{array}$ & & & & \\
\hline 1 & \multicolumn{2}{|c|}{ na } & 10,995 & 6.84 & \multicolumn{2}{|c|}{ na } & 6.84 & 1,137 & 690 & Straight \\
\hline 2 & \multicolumn{2}{|c|}{ na } & 8,414 & 8.71 & 7,076 & 7.01 & 7.86 & 805 & 808 & Split \\
\hline 3 & \multicolumn{2}{|c|}{ na } & 8,738 & 5.50 & 6,192 & 5.09 & 5.30 & 900 & 578 & Split \\
\hline 4 & \multicolumn{2}{|c|}{ na } & 5,493 & 2.99 & 7,081 & 4.84 & 3.91 & 593 & 277 & Split \\
\hline 5 & 7,260 & 5.51 & 8,230 & 5.63 & 10,677 & 6.37 & 5.83 & 832 & 602 & Jagged \\
\hline 6 & 6,868 & 4.39 & 6,591 & 4.41 & 9,107 & 4.95 & 4.58 & 799 & 505 & Jagged \\
\hline 7 & 7,307 & 4.12 & 8,259 & 4.84 & 10,446 & 6.04 & 5.00 & 756 & 376 & Jagged \\
\hline 8 & 7,468 & 5.71 & 5,846 & 3.57 & 9,402 & 4.80 & 4.70 & 774 & 371 & Split \\
\hline 9 & 6,164 & 4.42 & 7,872 & 4.98 & 9,829 & 5.43 & 4.94 & 755 & 418 & Jagged \\
\hline 10 & 9,015 & 4.92 & 8,946 & 5.57 & 9,269 & 5.49 & 5.33 & 962 & 589 & Straight \\
\hline 11 & 10,342 & 4.12 & 11,150 & 5.35 & 10,781 & 4.44 & 4.64 & 1,011 & 421 & Jagged \\
\hline 12 & 6,498 & 3.17 & 5,263 & 2.94 & 5,084 & 3.49 & 3.20 & 611 & 372 & Split \\
\hline 13 & 10,146 & 2.86 & 7,970 & 2.45 & 7,624 & 2.51 & 2.61 & 862 & 235 & Straight \\
\hline 14 & \multicolumn{2}{|c|}{ na } & 6,377 & 2.96 & 7,913 & 2.90 & 2.93 & 604 & 243 & Jagged \\
\hline 15 & 11,150 & 2.96 & 11,226 & 0.80 & 10,106 & 0.74 & 0.79 & 1,162 & 78 & Jagged \\
\hline 16 & 9,240 & 0.83 & 8,136 & 1.64 & 8,507 & 1.71 & 1.67 & 771 & 144 & Straight \\
\hline 17 & 9,852 & 1.66 & 10,227 & 0.84 & 10,244 & 0.86 & 0.84 & 983 & 86 & Jagged \\
\hline 18 & 9,223 & 0.01 & 9,846 & 0.01 & 8,038 & 0.00 & 0.01 & 997 & 0.54 & Straight \\
\hline 19 & 8,305 & 4.75 & 9,096 & 5.06 & 7,630 & 4.51 & 4.78 & 901 & 500 & Straight \\
\hline 20 & 8,744 & 4.16 & 6,158 & 3.69 & 11,081 & 5.59 & 4.48 & 685 & 369 & Jagged \\
\hline 21 & 8,547 & 5.31 & 7,064 & 4.63 & 5,771 & 4.18 & 4.71 & 734 & 506 & Straight \\
\hline
\end{tabular}

Figure 8 shows when the strain at failure and failure load is compared for all the coupons that the coupons that failed at low levels of load also did so at lower levels of strain as expected with a linear elastic brittle material such as CFRP. Therefore, the coupons that had lower ultimate tensile load levels were not able to achieve their full average strain capacity before failure. There was likely some failure in some fibers of the coupon early on that lead to the total fracture of the coupon.

Figure 8. Strain at failure vs. peak stress.

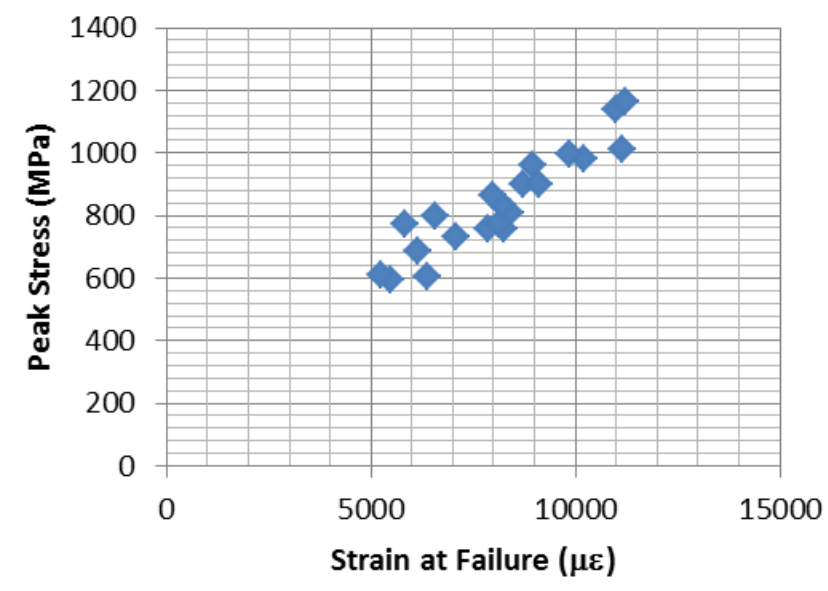


In addition, it can be seen that there is no significant change in stiffness under dynamic loading. Figure 9 illustrates the stress strain curve for statically tested Coupon \#18 and dynamically tested Coupon \#5. Both curves show the overall linear stress strain behavior expected of a CFRP coupon, however, the dynamic coupon does not illustrate the strictly linear behavior of the statically tested coupon. The static coupon modulus of 103.6 is $10 \%$ greater than the dynamic coupon modulus of 92.9 $\mathrm{GPa}$. The average tensile modulus of all the coupons is $96.7 \mathrm{GPa}$ which is close to the manufacture's reported $95.8 \mathrm{GPa}$.

Furthermore, there is indication of minor reduction of strain at failure (or elongation at break) for the dynamically tested coupons. Figure 10 shows the strain at failure based on strain gage 2 vs. the average strain rate. For the dynamically loaded coupons the average strain at failure is 0.008 with a standard deviation of 0.0018 . The manufactures' reported strain at failure and the average for the statically tested coupons is 0.01 , which is $20 \%$ greater than the dynamically tested coupons.

Figure 9. Stress $v s$. strain graph for static and dynamic coupon.

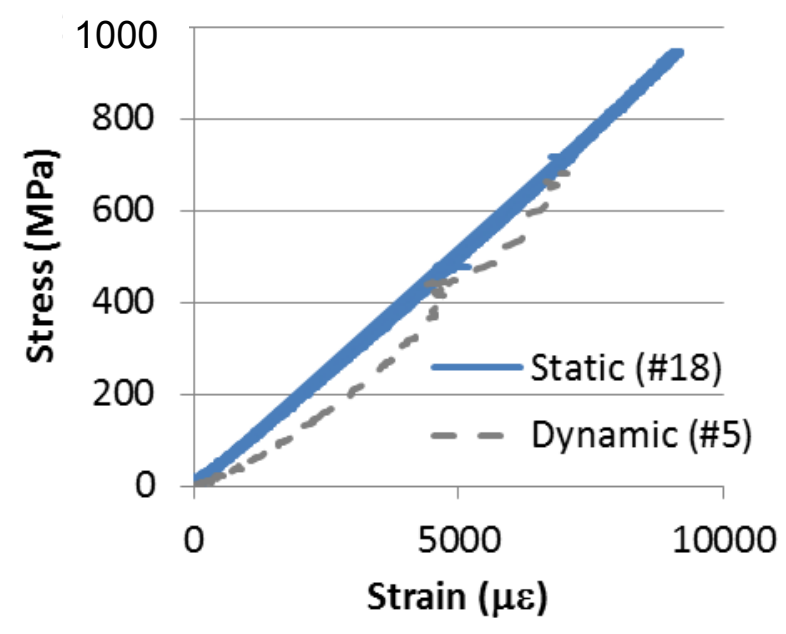

Figure 10. Strain at failure $v s$. average strain rate.

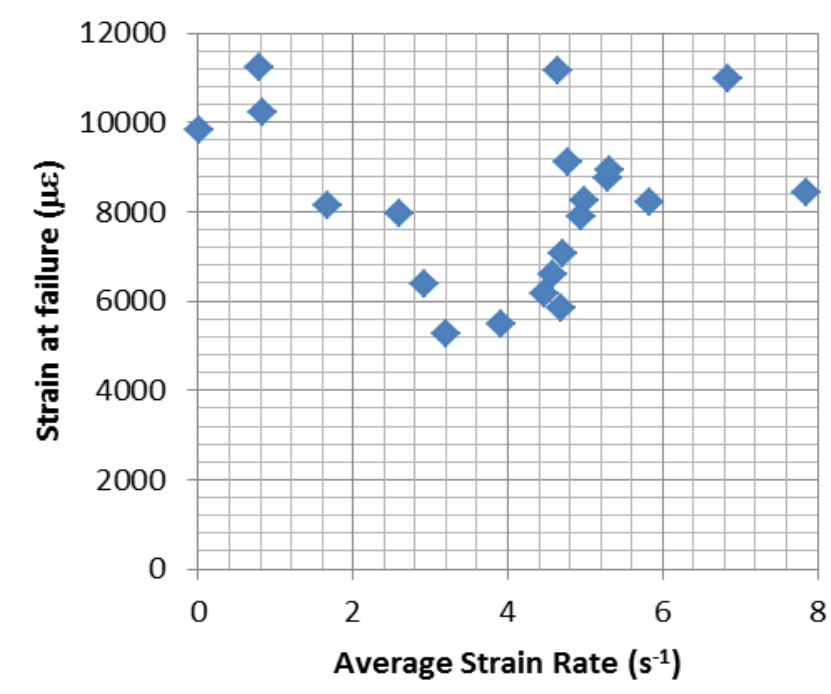

Figure 11 shows representative strain $v s$. time graphs for four coupons at different strain rates. The strain data in these graphs comes from strain gage 2 which was located in the center of the specimen. 
Coupon \#2, 5, 6, and 13 had approximate strain rates of 7.86, 5.83, 4.58 and $2.61 \mathrm{~s}^{-1}$, respectively. As can be seen in the figure, the actual strain rate of the tests varied due to the response of the specimen in the dynamic loader. Coupon \#13, which had the lowest approximate strain rate, dipped in the strain time response just before failure of the coupon. This dip is likely due to the movement and dynamics of the specimen and loader during testing. Despite of the dip, Coupon \#13 had the highest strength of the four coupons. Figure 12 shows high speed stills of Coupon \#5 and \#13. As seen for Coupon \#5 the specimen nearly exploded upon failure, fracturing into several pieces. For Coupon \#13 the specimen exhibited a more straight failure across the center of the coupon. Table 2 summarized the failures as "jagged" similar to Coupon \#5 where fibers fractures in different locations, "straight" similar to Coupon \#13 where a single horizontal fracture line crossed all fibers, and "split" where a two horizontal fracture lines crossed the specimen in two different locations.

Figure 11. Strain $v s$. time graphs for four representative coupons.

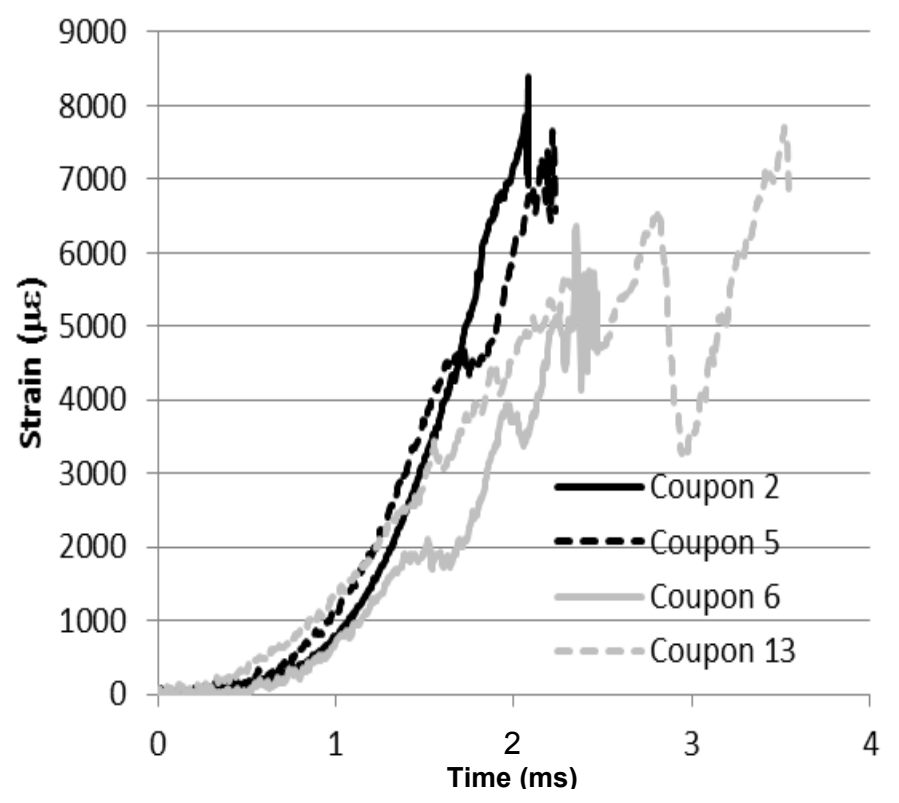

Figure 12. High speed failure stills of Coupon \#5 (left) and Coupon \#13 (right).
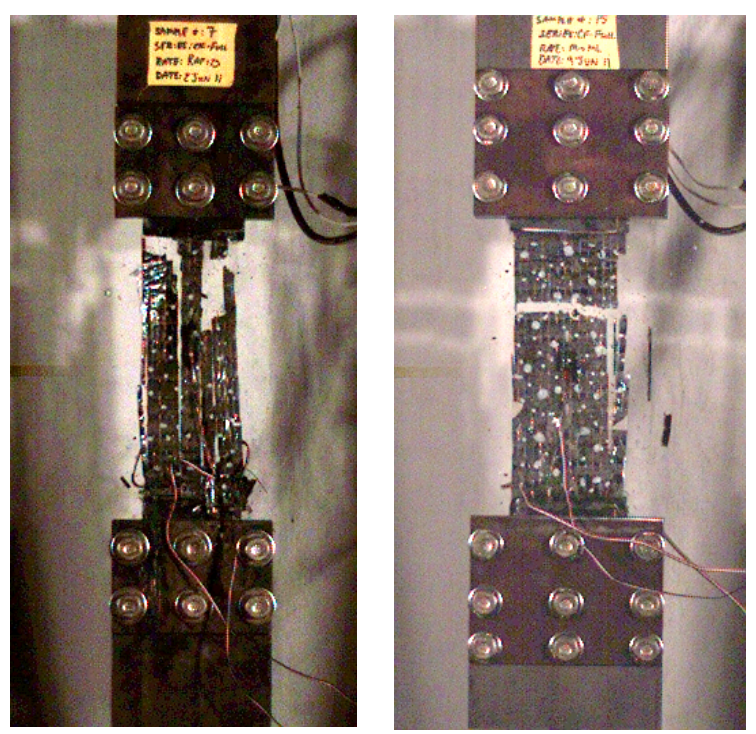
This research conducted tensile tests of 21 CFRP coupons using a hydraulically powered dynamic loader. The strain rates ranged from 0.0015 to $7.86 \mathrm{~s}^{-1}$ and are representative of strain rates that may occur in CFRP during a blast event. The results of the testing showed that there is no increase in the tensile strength of the CFRP at the higher strain rates. In addition there was greater scatter in the peak stress measured in the coupon tests. The coupons tested with an average tensile strength of $840 \mathrm{MPa}$ with a standard deviation of $161 \mathrm{MPa}$. The average strength is slightly less, and the scatter slightly more, than would be expected based on manufactures' provided data. The possible reasons are the hand lay-up manufacture of the coupons or the rate of loading which could lead to reduction in the ability for the CFRP to evenly distribute load among the fibers when dynamically loaded. Coupons which failed at a lower level of load, also failed at a lower level strain. Furthermore, due to the nature of the hydraulic test setup the rate of the dynamic load was not constant, which may have led to more scatter in the results. In addition, there was a $10 \%$ reduction in tensile modulus of the dynamically tested coupons and a $20 \%$ reduction in the strain at failure. Because of the wide scatter in the test data, it is difficult to determine if there is a need to account for strain rate effects in CFRP used in blast mitigations.

\section{Acknowledgments}

This research effort was supported by the Science and Technology Directorate of the Department of Homeland Security. Permission to publish was granted by the Department of Homeland Security and the Director, Geotechnical \& Structures Laboratory.

\section{Author Contributions}

Sarah L. Orton-In charge of research project and writer of paper.

Vincent P. Chiarito-In charge of testing of specimens.

Christopher Rabalais-Tested specimens.

Matthew Wombacher-Analyzed specimen test data.

Stephen P. Rowell-Designed and Constructed test setup.

\section{Conflicts of Interest}

The authors declare no conflict of interest.

\section{References}

1. Orton, S.; Chiarito, V.P.; Minor, J.K.; Coleman, T.G. Experimental testing of CFRP-strengthened reinforced concrete slab elements loaded by close-in blast. J. Struct. Eng. 2013, 140, doi:10.1061/(ASCE)ST.1943-541X.0000821.

2. Kim, J.H.H.; Yi, N.H.; Kim, S.B.; Choi, K.; Park, J.C. Experiment study on blast loading response of FRP-retrofitted RC slab structures. In Proceedings of the Second Asia-Pacific Conference on FRP Structures, Seoul, Korea, 9-11 December 2009.

3. Muszynski, L.C.; Purcell, M.R. Composite reinforcement to strengthen existing concrete structures against air blast. J. Compos. Constr. 2003, 7, 93-97. 
4. Razaqpur, A.G.; Contestabile, E.; Tolba, A. Experimental study of the strength and deformations of carbon fibre reinforced polymer (CFRP) retrofitted reinforced concrete slabs under blast load. Can. J. Civ. Eng. 2009, 36, 1366-1377.

5. Wu, C.; Oehlers, D.J.; Rebentrost, M.; Leach, J.; Whittaker, A.S. Blast testing of ultra-high performance fibre and FRP-retrofitted concrete slabs. Eng. Struct. 2009, 31, 2060-2069.

6. Lu, B.; Silva, P.; Nanni, A.; Baird, J. Retrofit for blast-resistant RC slabs with composite materials. In SP-230: 7th International Symposium on Fiber-Reinforced (FRP) Polymer Reinforcement for Concrete Structures; Busel, J.P., Walkup, S.L., Shield, D.D.G.C.K., Eds.; ACI: Kansas City, MO, USA, 2005.

7. Biggs, J. Introduction to Structural Dynamics; McGraw-Hill: New York, NY, USA, 1964.

8. Mosallam, A.S.; Mosalam, K.M. Strengthening of two-way concrete slabs with FRP composite laminates. Constr. Build. Mater. 2003, 17, 43-54.

9. UFC 3-340-02, Uniform Facilities Criteria (UFC): Structures to Resist the Effects of Accidental Explosions; U.S. Department of Defense: Washington, DC, USA, 5 December 2008.

10. Nedjar, B.; Kotelnikova-Weiler, N.; Stefanou, I. Modeling of unidirectional fibre-reinforced composites under fibre damage. Mech. Res. Commun. 2014, 56, 115-122.

11. Ascione, L.; Berardi, V.P.; D'Aponte, A. Creep phenomena in FRP materials. Mech. Res. Commun. 2012, 43, 15-21.

12. Sierakowski, R.L. Strain rate effects in composites. Appl. Mech. Rev. 1997, 50, 741-761.

13. Jacob, G.C.; Starbuck, J.M.; Feller, J.F.; Simunovic, S.; Boeman, R.G. Strain rate effects on the mechanical properties of polymer composite materials. J. Appl. Polym. Sci. 2004, 94, 296-301.

14. Wisnom, M.R. Size effects in the testing of fibre-composite materials. Compos. Sci. Technol. 1999, 59, 1937-1957.

15. Welsh L.M.; Harding, J. Effect of Strain-rate in the tensile failure of woven reinforced polyester resin composites. J. Phys. Colloq. 1985, 46, C5-405-C5-414.

16. Al-Salehi, F.A.R.; Al-Hussani, S.T.S.; Huston, M.J. Experimental investigation into the strength of angle ply GRP tubes under high rate of loading. J. Compos. Mater. 1989, 23, 288-305.

17. Gilat, A.; Goldberg, R.K.; Roberts, G.D. Experimental study of strain-rate-dependent behavior of carbon/epoxy composite. Compos. Sci. Technol. 2002, 62, 1469-1476.

18. Shokrieh, M.M.; Omidi, M.J. Tension behavior of unidirectional glass/epoxy composites under different strain rates. Compos. Struct. 2009, 88, 595-601.

19. Asprone, D.; Cadoni, E.; Prota, A.; Manfredi, G. Strain-rate sensitivity of a pultruded E-glass/polyester composite. J. Compos. Constr. 2009, 13, 558-564.

20. Fyfe "Tyfo SCH-41 Composite Data Sheet". Available online: http://www.fyfeco.com/Products/ /media/Files/Fyfe/2013-Products/Tyfo\%20SCH-41.ashx (accessed on 24 March 2014).

21. Rowell, S.P.; Grey, G.E.; Woodson, S.C.; Hager, K.P. High Strain Rate Testing of Mechanical Couplers; Technical Report ERDC TR-09-8: U.S. Army Engineer Research and Development Center, Hanover, NH, USA, September 2009.

(C) 2014 by the authors; licensee MDPI, Basel, Switzerland. This article is an open access article distributed under the terms and conditions of the Creative Commons Attribution license (http://creativecommons.org/licenses/by/3.0/). 